TERRA. Revista de Desarrollo Local e-ISSN: 2386-9968

Número 8 (2021), 767-775

DOI 10.7203/terra.8.21053

IIDL - Instituto Interuniversitario de Desarrollo Local

\title{
Reseña. Idiomas orientales, lenguas occidentales. Redescubrir China a través de los idiomas
}

\author{
Fang Han \\ Universidad de Estudios Extranjeros de Tianjin (China) \\ fanghan729@gmail.com
}

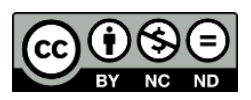

Esta obra se distribuye con la licencia Creative Commons

Reconocimiento-NoComercial-SinObraDerivada 4.0 Internacional 


\section{SECCIÓN RESEÑAS}

\section{Reseña. Idiomas orientales, lenguas occidentales. Redescubrir China a través de los idiomas}

Resumen: China y su cultura siempre han sido consideradas muy lejanas y diferentes, e incluso aisladas del mundo occidental; y la lengua china tiene la corona de ser "el idioma más difícil" en la mente de mucha gente. Hoy en día, bajo la globalización y el aumento de la importancia del papel que juega China en el mundo, mucha gente tiene curiosidad por esta tierra. Pero la distancia y las tópicos sobre este país impiden muchas veces el acercamiento adecuado a China. Por medio de este libro de divulgación científica, se pretenden exponer muchas de las múltiples relaciones existentes entre la cultura china y la occidental, en diferentes épocas y espacios, intentando responder así a algunas de las preguntas más habituales que tienen los lectores sobre la lengua y la cultura de este país. Es más, seguramente, se descubrirá una China diferente de la conocida hasta el momento.

Palabras clave: lengua china, lenguas europeas, comida china, relaciones culturales.

Recibido: 10 de junio de 2021

Devuelto para revisión: -

Aceptado: 10 de junio de 2021

\section{Referencia / Citation:}

Han, F. (2021). Reseña. Idiomas orientales, lenguas occidentales. Redescubrir China a través de los idiomas. TERRA. Revista de Desarrollo Local, (8), 767-775. DOI 10.7203/terra.8.21053 
Zining Zheng

IDIOMAS ORIENTALES, LENGUAS OCCIDENTALES. REDESCUBRIR CHINA POR MEDIO DE LOS IDIOMAS

\author{
(东言西语在语言中重新发现中国)
}

Lanzhou, Duanghuang (China). Literatura \& Art, 2020, 307 páginas

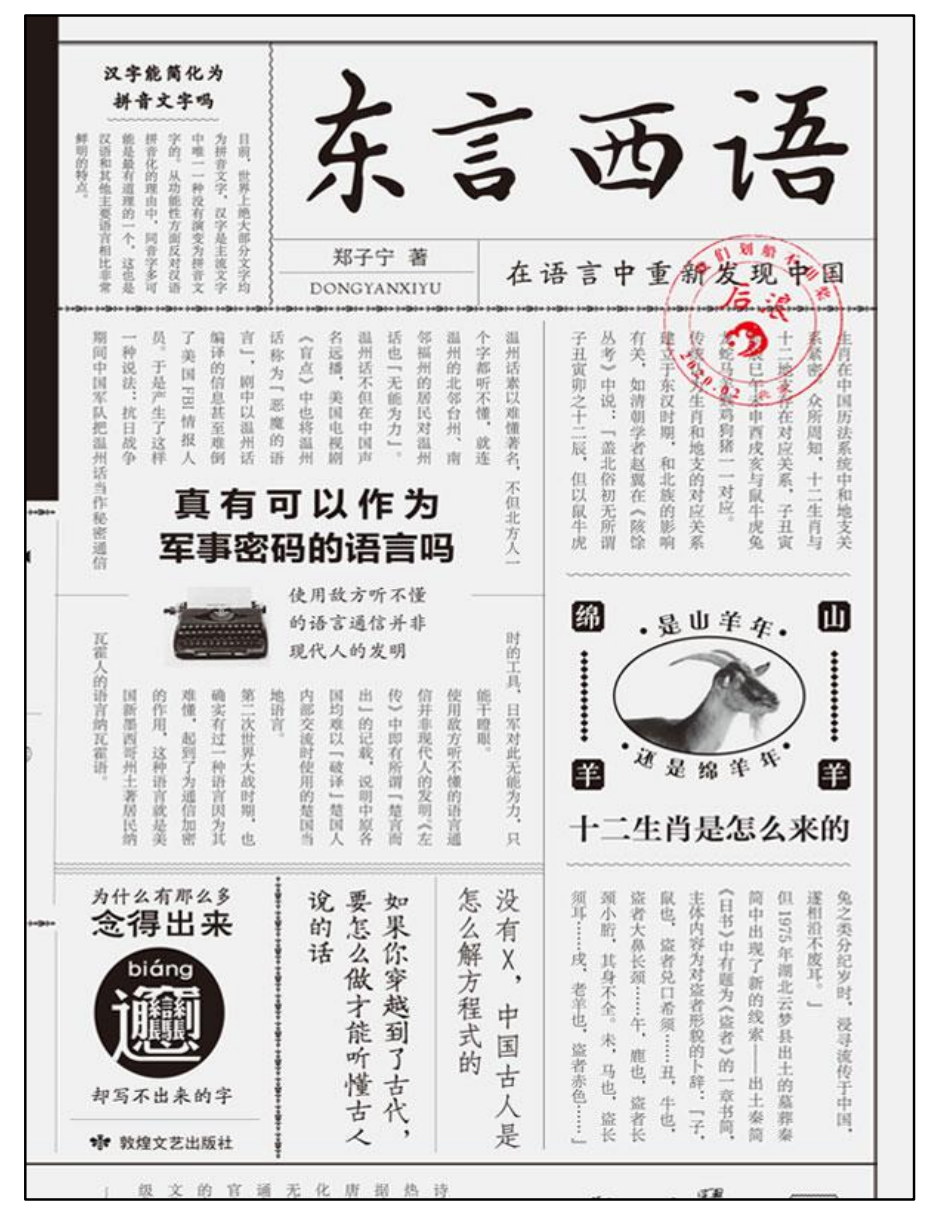

¿Es año de oveja o de cabra? ¿Por qué los chinos no sustituyen sus caracteres por transcripciones con letras latinas? ¿La comida china que comemos en España es auténtica? ¿Todos los chinos hablan el mismo chino? Son preguntan que se hacen frecuentemente en España.

En este libro de recopilación de artículos, se pueden encontrar algunas respuestas. Aunque es un libro de divulgación científica, la mayoría de las informaciones tienen fuentes fiables y el autor escribe con objetividad, por ejemplo, en el apartado que comenta si es año de cordero o de oveja, después de estudiar abundantes documentos históricos, nos cuenta una realidad, no su opinión, que es, ambas afirmaciones son correctas, pero hay una preferencia en diferentes zonas. No obstante, también se notan los defectos que existen en el apartado de lenguas europeas, pero a los potenciales lectores este no es el contenido más interesante de la obra, por lo que dejaremos estos aspectos de lado.

Lamentablemente, no hay traducción al español de este libro todavía, pero a través de la presente reseña esperamos que la curiosidad por China de los lectores españoles pueda aumentar, y, además, ofrecer algunas informaciones interesantes para que estos se sientan más cercanos a esta cultura lejana.

\title{
Ideograma frente a fonograma
}

Una de las dificultades que tiene el idioma chino para los extranjeros son sus caracteres: hay que memorizar los trazos, la pronunciación y los significados; por si fuera poco, cuando se ponen dos (o más) caracteres juntos, estos pueden cambiar de significado, y aún peor, hay 3500 caracteres con uso frecuente. Ante esta situación, no es extraño que haya muchas personas que prefieren utilizar la opción denominada "pinyin", es decir, la transcripción de carácteres con letras latinas. 
En realidad, no es una idea nueva: según el autor de la obra que estamos reseñando, en la dinastía Tang (618-907), los Han en el Imperio Tibetano utilizaron su fonograma al transcribir el chino, es decir, apuntaron la pronunciación del chino con las letras tibetanas. Después de conquistar Dunhuang, los tibetanos construyeron institutos de sutras de budas, donde hicieron que los Han copiaran los sutras escritos en tibetano. Estos Han, que saben la lengua tibetana, no solo firman los documentos con la transcripción en letras tibetanas de su nombre, sino también dejan muchos textos escritos con este sistema. Pero con el retiro de los tibetanos de esta zona geográfica, se dejó de utilizar esta escritura.

Existen otras transcripciones, como las empleadas entre los musulmanes de origen hui, una etnia musulmana de China. Una de ellas empleó la transcripción con letras árabes ya en el siglo XIII. Desde entonces y hasta el siglo XIX, dado que había muchos analfabetos en China, sobre todo en la zona noroeste donde habitaban (y habitan todavía) muchos musulmanes hui, algunos de ellos, para solucionar problemas que se traían por no conocer caracteres chinos, utilizaron letras árabes para escribir el chino que hablaban. Este tipo de escritura se llama “xiaor jing” (小儿经, que significa “escritura infantil”), y todavía se utiliza entre algunas etnias musulmanas chinas para enseñar el Corán a los niños.

A finales del siglo XIX, parte de los hui se trasladaron hasta Asia Central y los aborígenes los llaman "dunganos". Por la influencia soviética, estos utilizan las letras cirílicas para transcribir el chino que hablan, y este idioma se usa hasta hoy día, integrando durante épocas palabras rusas, árabes, persas, etc.

Tabla 1. La poesía de Zhao y su traducción de Henry Rogers

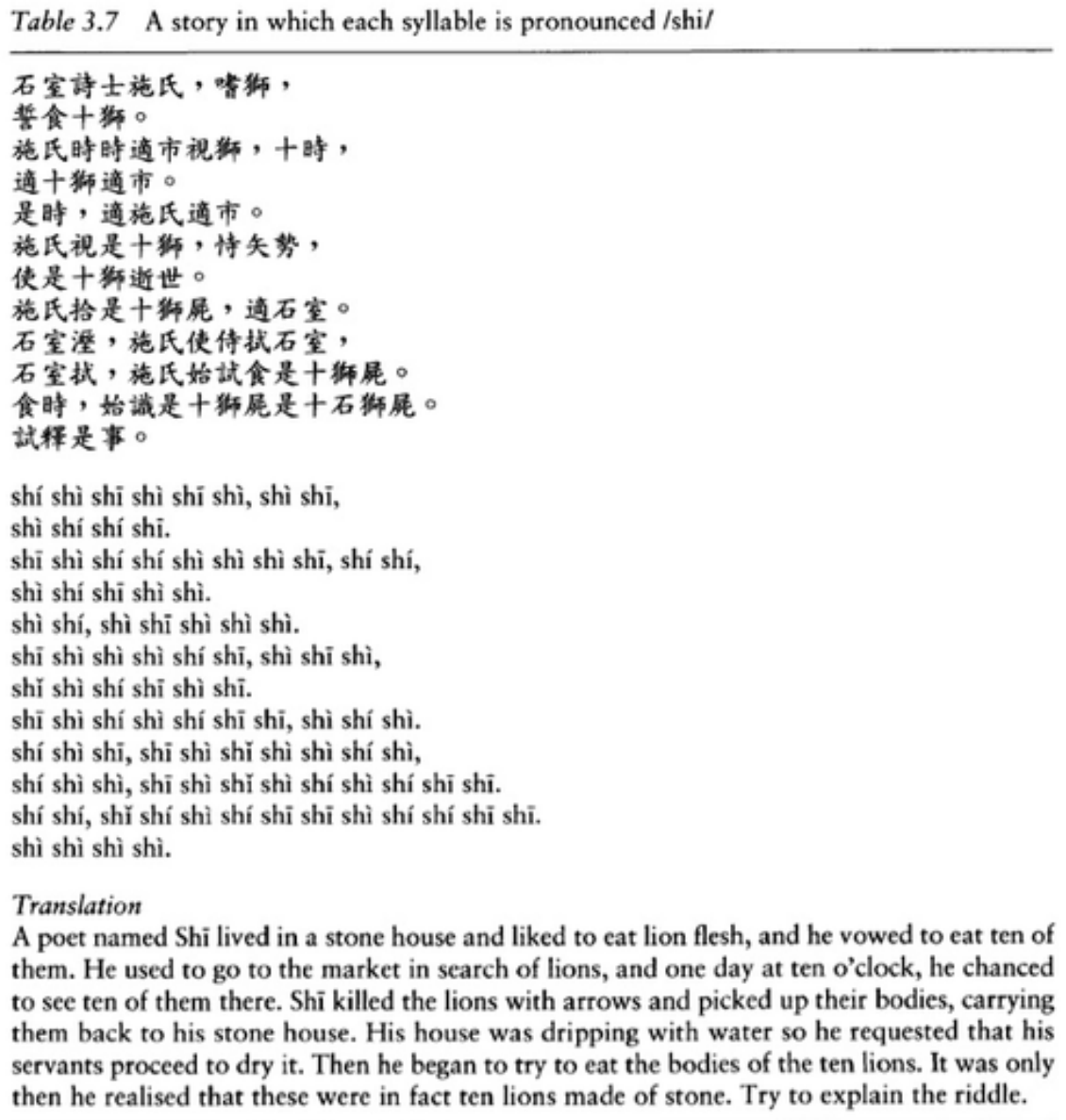


Después de ver tantas transcripciones que funcionan bien, parece que no es imposible la latinización de los caracteres chinos. El autor Zheng nos da dos nuevos ejemplos para demostrar algunos resultados más. Uno es una prosa que hizo Zhao Yuanren, uno de los lingüistas más famosos de China, para responder a la corriente que apareció en los años 50 del siglo pasado de la latinización del chino (Figura 1).

Es un ejemplo extremo, pero para nada equivocado, ya que en todas las lenguas hay homonimias, y en un idioma como el chino, la sustitución de los caracteres causaría más confusión que otra cosa. El ejemplo real que ofrece el autor nos demuestra el posible precio de esta hipótesis de sustitución. Durante la construcción de la autopista Gyeongpu (Corea del Sur), hubo un accidente causado por dos palabras homónimas: 방수 (bangsu), corresponden a dos palabras de origen chino, 防水 (fángshuǐ) y 放水(fàngshuǐ), en donde una significa "impermeabilizar" y la otra, "dejar salir el agua", que representan sentidos completamente contrarios.

\section{China no está tan lejos}

Entonces, ¿es imposible la latinización del chino? ¿Hay que estudiar los dibujos sí o sí? Parece que sí, pero las letras latinas pueden facilitar mucho el aprendizaje del chino. De hecho, esta manera auxiliar apareció hace ya bastantes siglos, con el fin de evangelización, entre los misioneros europeos que llegaron a China. Durante el siglo XVI y XVII, entre estos, surgió una corriente con tendencia a crear sistemas de transcripción del chino con letras latinas. Matteo Ricci y Michele Ruggieri son los que proporcionan el primer sistema de transcripción latina del chino: en el diccionario portugués-chino que redactan, aplican las letras latinas para señalar la pronunciación de las palabras chinas correspondientes, como se puede observar en la Figura 2, en donde en la segunda columna se observan las transcripciones fonéticas.

Figura 2. Una página del manuscrito del Diccionario portugués-chino

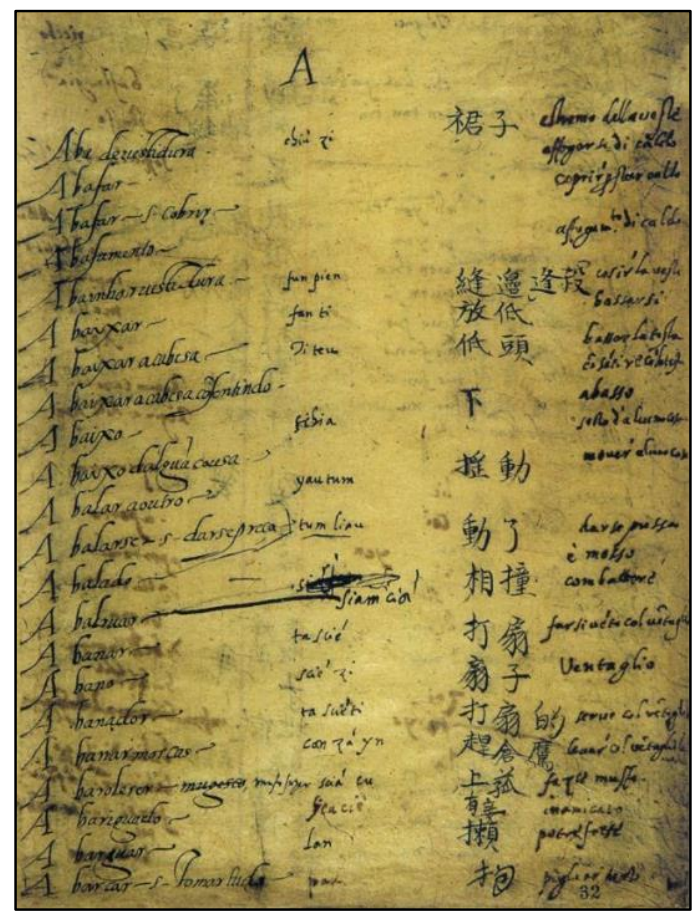

Fuente: http://www.accademiadeicatenati.it/viaggio-all-interno-di-un-antico-manoscritto--1.html 
Otro sistema de transcripción es el creado Nicolas Trigault en su obra 'Xiru ermu zi' (西 儒耳目资 $)^{1}$, que es el sistema con mayor influencia en China.

Figura 3. Una página de Xiru ermu zi

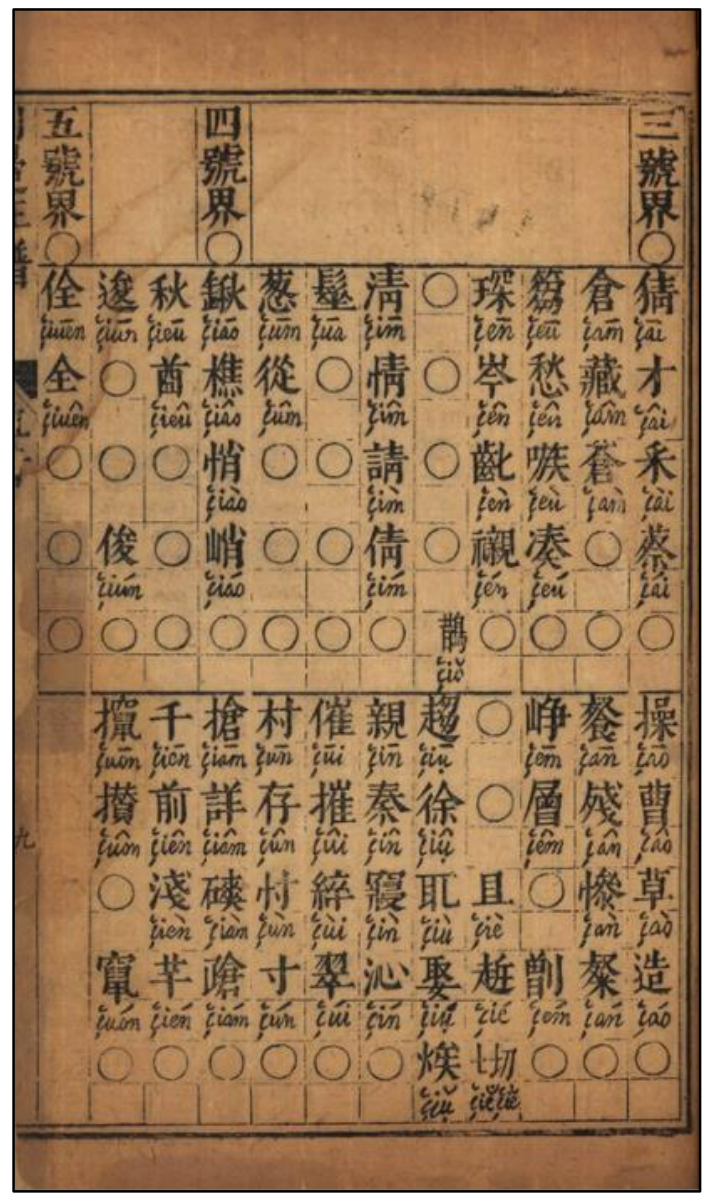

Fuente: Library of Congress. https://www.wdl.org/zh/item/15114/view/1/13/

Como indica Zheng (2020), según la lengua nativa que tenían y el acento del sitio donde estaban los misioneros, la transcripción era diferente. Por ejemplo, en los dos sistemas que hemos mencionado, se refleja la pronunciación del mandarín de finales de la dinastía Ming, y también hay otros que muestran dialectos de otras zonas chinas, tales como Fuzhou, Haikou, Wenzhou, etc. Pero la transcripción más usada y más famosa es el sistema Wade-Giles, de Thomas Francis Wade, sinólogo inglés. No obstante, este sistema es muy diferente del pinyin, o sea, la transcripción que se usa hoy día: cuando escuhamos por primera vez a los españoles hablar de "Chiang Kai-shek", no es fácil de entender ni tan siquiera viéndolo, porque en el pinyin chino se dice "Jiang Jieshi". Muchos de los lectores españoles podrían haber visto alguna vez "Beijing" en vez de "Pekín", "Guangdong" en vez de "Cantón", pero esta discordancia de transcripción fonética no es por Wade, sino por la transcripción del sistema postal chino.

\footnotetext{
1 "An Aid to the Eye and Ear of Western Scholars". Esta traducción al inglés cito de la página web del Instituto Ricci de la Universidad de San Francisco:

http://riccilibrary.usfca.edu/view.aspx?catalogID=16394.
} 
En 1906 se celebró la Asamblea Conjunta de los Correos Imperiales en Shanghái. Como el sistema de Wade que se estaba utilizando se marca con la lengua inglesa, los franceses, que son los que controlaban el mundo postal chino en aquella época, crearon un nuevo sistema de transcripción basándose en el de Wade, y este sistema iba adaptándose a diferentes lenguas europeas según su propio carácter (por ejemplo, Peking a Pekín, Canton a Cantón).

Después de varias generaciones de trabajo, en los años 80 del siglo pasado, el sistema de transcripción de chino con letras latinas alcanzó cierta consolidación, con normas internacionalmente reconocidas, y que es el pinyin que usamos en la actualidad. Este sistema, aunque no puede sustituir los caracteres chinos, ayuda no solo a los extranjeros, sino también a los propios chinos en el estudio del chino estándar.

\section{El chino no está aislado}

En la mente de muchos europeos, tanto China como su cultura es otro mundo completamente distinto y aislado. Pero la realidad es que los chinos y los europeos compartimos algunas palabras sin saberlo. Puede que algunos lectores piensen: claro, tenemos 'tofu', 'kung-fu', 'tifón', etc. En realidad, hay más: 'kétchup', 'soja', 'biombo', 'té', etc., algunos de ellas llegan al español a través del japonés, mientras que otras proceden de dialectos chinos. ¿Pero en chino hay palabras de lenguas europeas?

Por supuesto, además, había una lengua pidgin de inglés en el siglo XIX. En aquella época colonial, los ingleses tenían una clara influencia socioeconómica y cultural en Shanghái, en donde había muchos negocios y actividades económicas de todo tipo. Para poder aprender inglés, los chinos de Shanghái y de las zonas alrededores inventaron un sistema de transcripción al inglés con caracteres chinos, que se pronunciaba según el acento de Ningbo (un sitio cerca de Shanghái). En 1879, la editorial Commercial Press (China) incluso publicó la obra: Instrucciones de inglés (英字指南), en la que se utilizaban los caracteres chinos para anotar la pronunciación de las palabras inglesas. Pero hay que saber el dialecto wu, que se habla por Shanghái, Zhejiang y Suzhou, para poder saber cómo pronunciar adecuadamente los caracteres. Este pidgin inglés sin regla gramatical ni pronunciación correcta, ha dejado de ser usado con el tiempo, pero sí que ha dejado huellas tanto en el chino como en el inglés (incluso en el español). Por ejemplo, la expresión Long time no see, viene de la frase china 好久不见 (mucho tiempo sin ver); chin chin viene de 请 [qǐng], que significa “por favor" (Zhou, 2003). Y en chino tenemos algunas palabras de origen europeo con traducción fonética y significado literal curioso, tales como 香波 [xiāngbō] “olas perfumadas", que es shampoo; 马达 [mǎdá] "llega (como un ) caballo", que es motor; y 麦克风 [màikèfēng] “viento de Mike”, que se refiere a microphone. También hay otros que no tienen mucho sentido literal, por ejemplo 巴士 [bāshì], bus; 吉他 [jíta], guitarra; 吐司 [tǔsī], toast; etc. (Xie, 2019).

Al igual que ocurre con el idioma, en la comida también podemos señalar la influencia entre Europa y China: en China, tomar café ya es una costumbre de mucha gente; a muchos nos gustan las tostadas para desayunar; hay restaurantes españoles, italianos, franceses, entre muchos otros estilos europeos, en muchas ciudades chinas. En Europa, además de muchos restaurantes chinos en casi todas las ciudades, hay 'tofú' y salsa de 'soja', e incluso ‘wantán' congelado en supermercados españoles.

Pero muchas veces los españoles se plantean ¿son auténticas estas comidas chinas? Y las respuestas pueden dividirse generalmente en dos grupos: los del sur te dicen que sí, y los 
del norte te dicen que es comida del sur. Es verdad, la mayoría de los chinos que hacen negocios en Europa son de Zhejiang, Fujian y Cantón, tres provincias del sur de China, y la característica más destacada de su comida es la dulzura. Es el porqué de que el sabor agridulce se la primera impresión que deja la comida china a muchos europeos: el pollo al limón y el pollo agridulce son los platos chinos más populares en Europa. Pero ¿es verdad que a los del sur les gusta más dulce y los del norte, salado? La respuesta es, no, ni histórica, ni actualmente. Como apunta Zheng (2020), Shen Kuo, un escritor de la dinastía Song del Norte (960-1127), describe el gusto general de sabor de los chinos como “a la gente del sur le gusta comida salada, y a la del norte, dulce” (大抵南人嗜咸, 北人 嗜甘), justamente al revés de lo que cree la sociedad actual.

En la antigüedad, tanto la miel como el azúcar eran materiales muy caros: la miel se tuvo que importar, y la caña de azúcar entró en China durante la dinastía Han (202 a.C.- 8 d. C.), pero no se utilizó para producir azúcar, sino como fruta o para hacer zumo. La técnica de producir azúcar con caña entró en China en la dinastía Tang, aun así, no se podía producir suficiente azúcar ni cuando llegó la época de Song y Yuan (960-1368). Luego, el azúcar era para población con más poder adquisitivo, por lo menos, de las ciudades ricas, precisamente situadas, en mayor porcentaje, en el norte de China. Eran estos, fundamentalmente, los habitantes que podían disfrutar del sabor dulce. Al llegar el final de la dinastía Song del Norte, por la guerra en el Norte, tanto la corte como población con más recursos, emigraron al sur, y con ellos se llevaron el gusto por las comidas dulces. Desde entonces, mientras que el sur se "endulzaba" con el desarrollo económico, el norte padecía numerosos conflictos, lo que suponía que su población tuviera complicado disfrutar del azúcar.

En la actualidad, la situación ha cambiado considerablemente y podemos ver muchos platos dulces en la cocina tradicional del norte de China, aunque la mayoría de los platos dulces que se comen hoy día en el norte de China no son nativos: algunos se traen desde el sur, mientras que otros son, por ejemplo, de origen musulmán: en Pekín hay un plato tradicional que se llama 它似蜜 [tāsìmì], en sentido literal “esto es como la miel”, que es cordero salteado con miel, cuyo nombre viene posiblemente de la frase árabe attasmīyyah (التسمية).

Hablando de la miel, esta palabra proviene de la latina 'mel', y según López Chala (2017), Olsen cree que el origen indoeuropeo de esta palabra es 'mełr'. Curiosamente, el carácter chino de miel es 蜜, cuya pronunciación es [mì], y, de acuerdo con Li (2011), muchos estudiosos creen que esta palabra tiene su origen en el idioma de Kucha, una de las lenguas tocarias en el que la miel se pronuncia [mit]. Es decir, la palabra de miel en chino tiene origen indoeuropeo como su hermana española. Luego, China nunca ha estado aislada ni muy lejos de Europa, porque desde hace miles de años comparten el mismo sabor dulce que nos regala a todos por igual la naturaleza.

\section{REFERENCIAS}

Feng, Z. (2011). ‘Romanización’ o ‘latinización'. China Terminology, 2(012).

Li, Y. y Li, B. (2011). La función de la lengua tocaria en el estudio de relaciones entre chino e indoeuropeo. Ciencia Lingüística, 10(6), 586-592.

Liu, C. y Gao, J. (2015). Origen del inglés Pidgin en China y su influencia. Educación filológica, (1), 128-129. 
López Chala, A. (2017). Los adjetivos en - u- en armenio clásico. Literatura y lingüística, (36), 313-326. Recuperado de: https://scielo.conicyt.cl/scielo.php?pid=S0716$58112017000200313 \&$ script $=$ sci_arttext\&tlng=e\#fn6.

Ministerio de Educación (2011). Normas de enseñanza de filología china en primaria y segundaria.

Rogers, H (2005). Writing Systems: A Linguistic Approach. Wiley-Blackwell, Nueva York.

Trigault, N. (1626). Xiru ermu zi. Recuperado de: https://www.wdl.org/zh/item/15114/view/1/13/.

Xie, R. (2019). Estudio cultural y lingüístico de Notación de la lengua inglesa en inglés pidgin de Ningbo del periodo tardío de la dinastía Qing. Editorial de la Universidad de Zhejiang, Hangzhou.

Zhou, Z. (2003). Primer glosario del inglés Pidgin en China. Ciencias Sociales de Cantón, (1), 77-84.

Fang Han

Universidad de Estudios Extranjeros de Tianjin (China) 